\title{
Honeybee venom possesses anticancer and antiviral effects by differential inhibition of HPV E6 and E7 expression on cervical cancer cell line
}

\author{
YONG-WAN KIM ${ }^{1,2}$, PANKAJ KUMAR CHATURVEDI ${ }^{3}$, SUNG NAM CHUN ${ }^{4}$, \\ YANG GU LEE ${ }^{4}$ and WOONG SHICK AHN ${ }^{5}$
}

\begin{abstract}
${ }^{1}$ School of Integrated Technology, Yonsei Institute of Convergence Technology, Yonsei University, Incheon;
${ }^{2}$ Cancer Rehab Laboratory, RH HealthcareSystems Inc., ${ }^{3}$ Catholic Research Institute of Medical Science, College of Medicine, The Catholic University of Korea, Seoul; ${ }^{4}$ Dong Sung Biopharm Co., Seoul;

${ }^{5}$ Wonkwang Institute of Interfused Biomedical Science, Wonkwang University, Iksan-si, Republic of Korea
\end{abstract}

Received May 8, 2014; Accepted July 14, 2014

DOI: $10.3892 /$ or.2015.3760

\begin{abstract}
Bee venom (BV) therapy is a type of alternative medical treatment used to treat various diseases in oriental medicine. The mechanisms underlying the effects of BV remain poorly understood. In the present study, we evaluated the antiviral effect of BV on cervical carcinoma cell lines (CaSki, HeLa, C33A and TC-1). BV treatments resulted in a more significant suppression of cell growth in HPV 16-infected cells (CaSki) and a lesser suppression in HPV 18-infected cells (HeLa). However, less suppression was observed in HPV-negative C33A cells. In $10 \mu \mathrm{g} / \mathrm{ml} \mathrm{BV-treated} \mathrm{CaSki}$ cells, the mRNA expression and protein levels of HPV16 E6 and E7 were significantly decreased by BV, while HPV18 E6 and E7 mRNA expression levels were not significantly altered by $10 \mu \mathrm{g} / \mathrm{ml} \mathrm{BV}$-treated HeLa cells. The antitumor effects of $\mathrm{BV}$ were in accordance with in vitro data, in restricting tumor growth in vivo and were much more effective on the suppression of tumor growth. Furthermore, the mRNA and protein expression levels of HPV16 E6 and E7 were decreased by BV in TC-1 tumors. These findings demonstrated the antiviral effects of BV in HPV-infected cervical cancer cells and the anticancer effects of BV in HPV16 E6/E7-expressed TC-1 tumors. Collectively, BV plays a differential role in suppressing HPV16-infected cells (CaSki cells) and HPV18-infected cells (HeLa cells) by the downregulation of E6/E7 protein of HPV16/18.
\end{abstract}

\section{Introduction}

Bee venom (BV) therapy is the part of apitherapy that utilizes $\mathrm{BV}$ in the treatment of inflammatory conditions (1). BV

Correspondence to: Dr Woong Shick Ahn, Wonkwang Institute of Interfused Biomedical Science, Wonkwang University, Iksan-si, Republic of Korea

E-mail: woongshickahn@gmail.com

Key words: human papillomavirus, honeybee venom, antiviral effects, cervical cancer has been used as a traditional medicine to treat back pain, rheumatism and skin diseases by its antibacterial, antiviral and anti-inflammatory effects (2-4). BV is a rich source of enzymes and peptides, including melittin, phospholipase A2 (PLA2), apamin, adolapin and mast cell-degranulating peptide (MCDP) (5-7). There are at least 18 active components in the venom which have some pharmaceutical properties (8). Among these compounds, melittin, a small linear peptide consisting of 26 amino acids, is the major potent toxin of $\mathrm{BV}$ (9), which comprises $\sim 50 \%$ of BV (10).

BV can induce apoptosis in synovial fibroblasts via caspase- 3 activation and inhibition of cyclooxygenase (Cox)-2 expression in human lung cancer cells (11). Moreover, several studies have demonstrated that $\mathrm{BV}$ and/or melittin have anticancer effects in prostate $(12)$, liver $(13,14)$, breast $(15)$, cervical (16) and renal cancer cells (17). Recently, it was shown that melittin can poke holes in the protective envelope that surrounds human immunodeficiency virus (HIV), and other viruses as well as tumor cells by melittin-loaded nanoparticles (18). Many viruses, including hepatitis B and C, rely on the same type of protective envelope and would be vulnerable to melittin-guided BV therapy. Secreted phospholipases A2 from BV have potent anti-HIV activities (19). A nanoscale delivery vehicle for cytolytic peptides was demonstrated by incorporating the non-specific amphipathic cytolytic peptide melittin into the outer lipid monolayer of a perfluorocarbon nanoparticle (20). The nanovehicles were delivered significant payloads of melittin i.v. and targeted and killed precancerous lesions in K14-HPV16 mice with squamous dysplasia and carcinoma harboring human papilloma virus (HPV) transgenic elements (E6 and E7 oncogenes). However, experiments demonstrating the molecular mechanisms of the antiviral effects of BV in cervical cancer cells have not been reported. It is becoming increasingly uncertain whether there are wide variations in tumorigenic inhibitory effects among different cell types.

In the present study, we investigated the anticancer effects of BV on cervical cancer cells well-known for having two viral oncogenic proteins, E6 and E7, that play a critical role in inducing cervical cancer. We observed that there is a signifi- 
cant difference in sensitivity to BV, and HPV16/18 E6/E7 are downregulated by BV in the cervical cancer cells. Moreover, the downregulation is likely to be dependent upon the cervical cancer cell line used. Thus, BV plays a differential role in suppressing HPV16-infected cells (CaSki cells) and HPV18infected cells (HeLa cells) by inducing cervical cancer cell growth arrests by the downregulation of E6/E7 protein of HPV16/18.

\section{Materials and methods}

Ethics statement. All procedures of animal research were conducted in accordance with the Laboratory Animals Welfare Act (protocol no. 8852), the Guide for the Care and Use of Laboratory Animals (protocol nos. 9025 and 21370), and the Guidelines and Policies for Rodent Experiment provided by the Institutional Animal Care and Use Committee (IACUC) of the School of Medicine, The Catholic University of Korea. The present study was reviewed and approved by the Catholic University of Korea's IACUC (CUMC-2012-0054-07: Effects of BV on the inhibition of HPV E6 and E7 expression in cervical cancer cells). All rodents used for surgeries were initially anesthetized using isoflurane in desiccators then followed by isoflurane as required.

Cell culture conditions. C33A (HPV-uninfected cervical cancer cell line), CaSki and HeLa (HPV-infected cervical cancer cell lines) were purchased from the Korean Cell Line Bank (KCLB; Seoul, Korea). TC-1 cells were prepared by transformation of C57BL/6 primary mouse lung cells with HPV16 E6/E7 oncogene and activated HRAS (21,22). All cell lines were incubated in RPMI-1640 cell culture medium supplemented with $10 \%(\mathrm{v} / \mathrm{v})$ heat-inactivated fetal bovine serum (FBS) and $1 \%$ penicillin/streptomycin (all from Gibco) at $37^{\circ} \mathrm{C}$ in a humidified $5 \% \mathrm{CO}_{2}$ atmosphere.

Cell viability assay. The cytotoxicity and sensitivity of BV was first determined by measuring the conversion of the tetrazolium salt 3-(4,5-dimethyl-2-thiazolyl)-2,5-diphenyl2H-tetrazolium bromide (MTT; Sigma) to formazan. Briefly, CaSki, HeLa and C33A were seeded $1 \times 10^{4}$ cells/well in 96-well culture plates and cultured overnight. The cells were then treated with $1-15 \mu \mathrm{g} / \mathrm{ml}$ of BV. The control group was treated with the same volume of phosphate-buffered saline (PBS). After 12 and $24 \mathrm{~h}$ of incubation, $20 \mu \mathrm{l}$ of MTT stock solution ( $2 \mathrm{mg} / \mathrm{ml}$ in PBS) was added to each well. After $4 \mathrm{~h}$ incubation at $37^{\circ} \mathrm{C}$, the supernatant was discarded and the precipitate was dissolved with $200 \mu 1$ of dimethyl sulfoxide (DMSO). The absorbance of the wells was measured at $570 \mathrm{~nm}$ using Soft Max ELISA (Molecular Devices, Sunnyvale, CA, USA). The optical density (OD) was calculated as the difference between the reference wavelength and the test wavelength. Percent of cell viability $=[$ A570 $\mathrm{nm}$ absorbance of drug-treated cells/A570 nm absorbance of control cells] x 100 .

Reverse transcription (RT)-PCR and real-time PCR (qRT-PCR) analysis. Total RNA was extracted from CaSki, HeLa and C33A cells or TC-1 tumors treated by BV using TRIzol (Invitrogen, Carlsbad, CA, USA) and purified using RNeasy columns (Qiagen, Valencia, CA, USA) according to the manufacturer's protocol. After processing with DNase digestion, clean-up procedures, RNA samples were quantified and stored in $10 \mu \mathrm{l}$ aliquot at $-80^{\circ} \mathrm{C}$ until use. For quality control, RNA purity and integrity were evaluated by denaturing gel electrophoresis, OD 260/280 ratio, and analyzed on Agilent 2100 Bioanalyzer (Agilent Technologies, Palo Alto, CA, USA). The cDNA was synthesized using PrimeScript reagent kit (Takara, Japan) according to the manufacturer's instructions. Briefly, $1 \mu \mathrm{g}$ of RNA was reverse-transcribed to cDNA using $200 \mathrm{U}$ moloney murine leukemia virus (M-MLV) reverse transcriptase and oligo(dT) primer in a total reaction volume of $20 \mu \mathrm{l}$ for $1 \mathrm{~h}$ at $37^{\circ} \mathrm{C}$. The cDNA was amplified using HPV16 E6, HPV16 E7, HPV18 E6 and HPV18 E7 primers. The E6 primers were 5'-GAGAACTGCAATGTTTCAG GAC-3' and 5'-CCACCGACCCCTTATATTATGG-3' for HPV-16, and 5'-AATACTATGGCGCGCTTTGA-3' and 5'-CTGGATTCAACGGTTTCTGG-3' for HPV-18. The E7 primers were 5'-GCAACCAGAGACAACTGATCTCTAC-3' and 5'-GGTCTTCCAAAGTACGAATGTCTACG-3' for HPV-16, and 5'-TGCATGGACCTAAGGCAA-3' and 5'-GCT GGGATGCACACCA-3' for HPV-18. Amplified products were analyzed using an image documentation system (GelDoc 2000) with image analysis software (Quantity One) (both from Bio-Rad, Hercules, CA, USA). DNA size markers (Fermentas, Pittsburgh, PA, USA) were run in parallel to validate the predicted sizes of the amplified bands. For qRT-PCR analysis, cDNA was amplified using these specific primers and SYBR Premix Ex Taq (2X) kit (Takara, Japan) according to the manufacturer's instructions. HPV E6/E7 expression analysis was carried out using LightCycler 480 II (Roche, Palo Alto, CA, USA) and gene expression raw data were extracted using the software provided by the manufacturer (BeadStudio v.3.0; Partek $^{\circledR}$ Genomics). HPV E6/E7 gene expression was determined compared to GAPDH gene expression.

Western blotting. For immunoblots, confluent monolayers of CaSki, HeLa and C33A or TC-1 tumors were lysed with cell extraction buffer (10 mM Tris, pH 7.4, $100 \mathrm{mM} \mathrm{NaCl}$, $1 \mathrm{mM}$ EDTA, $1 \mathrm{mM}$ EGTA, $1 \mathrm{mM} \mathrm{NaF}, 20 \mathrm{mM} \mathrm{Na} \mathrm{P}_{2} \mathrm{O}_{7}$, $2 \mathrm{mM} \mathrm{Na} \mathrm{VO}_{4}, 1 \%$ Triton $\mathrm{X}-100,10 \%$ glycerol, $0.1 \%$ SDS, $0.5 \%$ deoxycholate) (BioSource International, Camarillo, CA, USA) in the presence of protease inhibitors. Protein concentration was determined using the BCA protein assay (Bio-Rad). Electrophoration was performed on 10-12\% SDS-polyacrylamide gels for $2 \mathrm{~h}$, and the gels were then transferred onto PVDF membranes (Millipore, Temecula, CA, USA). Membranes were blocked in Tris-buffered saline with $0.1 \%$ Tween-20 (TBST) containing 5\% skim milk for $1 \mathrm{~h}$ at room temperature. After blocking, membranes were incubated for $1 \mathrm{~h}$ at room temperature or overnight at $4^{\circ} \mathrm{C}$ with polyclonal rabbit anti-HPV16/18 E6, anti-HPV16 E7 and anti-HPV18 E7, and monoclonal mouse anti- $\beta$-actin antibodies (both from Santa Cruz Biotechnology, Santa Cruz, CA, USA) in a 1:200500 dilution buffer (5\% skim milk in TBST). Membranes were washed three times with TBST and then incubated with goat anti-mouse IgG-HRP and goat anti-rabbit $\operatorname{IgG}(\mathrm{H}+\mathrm{L})$ HRP-conjugated antibodies (Zymed, San Francisco, CA, USA) for $1 \mathrm{~h}$ at room temperature. Immunoblots were developed with enhanced chemiluminescence agents according to the manufacturer's instructions (SuperSignal West Pico 
A

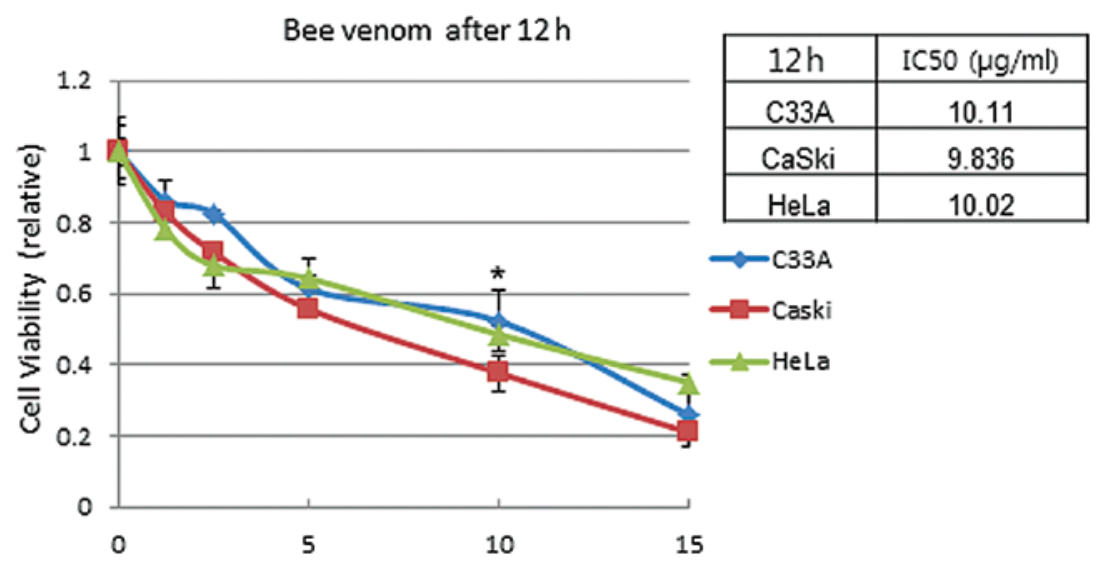

B

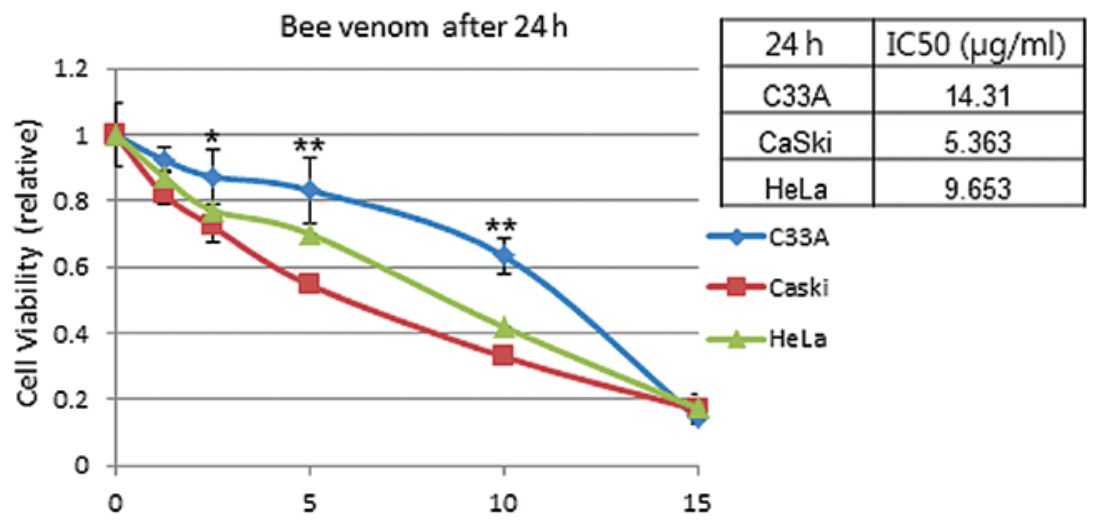

Figure 1. Growth-inhibitory effects of BV on various cervical carcinoma cell lines at different concentrations of BV. Cells (1x10 4 cells/well) were cultured in 96-well culture plates in triplicate overnight. The cells were then treated with $1-15 \mu \mathrm{g} / \mathrm{ml} \mathrm{BV}$. The control group was treated with the same volume of phosphate-buffered saline (PBS). After (A) 12 and (B) $24 \mathrm{~h}$ of incubation, cell viability was determined based on the MTT assay. Each bar represents a means $\pm \mathrm{SD}$ (vertical line) of three replicates. ${ }^{*} \mathrm{P}<0.05$ and ${ }^{* *} \mathrm{P}<0.001$ as compared with the control, respectively. $\mathrm{BV}$, bee venom.

Chemiluminescent Substrate; Pierce, Rockford, IL, USA) and exposed to imaging film.

Antitumor effects of TC-1 tumor models. TC-1 tumors were implanted in the abdomens of 4- to 5-week old female C57BL/6 mice by subcutaneous injection of $5 \times 10^{5}$ TC-1 cells in $100 \mu 1$ of serum and antibiotic-free DMEM media (Gibco-BRL). When tumors reached a volume of $150-200 \mathrm{~mm}^{3}$, mice were randomly assigned to one of three groups to receive PBS, $1 \mathrm{mg} / \mathrm{kg} \mathrm{BV}$ and $2 \mathrm{mg} / \mathrm{kg} \mathrm{BV}$ (5 mice/group). The first day of treatment was designated as day 1 . BV or PBS was administered three times via intra-tumoral injection (for TC-1 tumors, BV diluted in $100 \mu 1$ of PBS) on days 1,2 and 3. Tumor growth delay was assessed by taking measurements every day or every 2 days. Tumor volume was calculated by the following formula: Volume $=0.523 L W^{2}$, where $L$ is length and $W$ is width. Tumor responses to each treatment were compared by use of the Mann-Whitney test.

Statistical analysis. The data were obtained by three or more independent experiments and are expressed as means \pm standard error of the mean (SEM). Statistical comparisons were analyzed by Mann-Whitney test (non-parametric method) using StatView software (Abacus Concepts, Inc., Berkeley, CA, USA). Survival was assessed with the Kaplan-Meier method, and results were compared with a log-rank test SPSS software version 13.0 (SPSS Inc., Chicago, IL, USA). Statistical significance was defined as $\mathrm{P}<0.05$.

\section{Results}

Cell viability by $B V$ on $H P V$-infected cervical cancer cells. CaSki (HVP16-infected), HeLa (HPV18-infected) and C33A (HPV-negative) cells were treated by various concentrations of BV for 12 or $24 \mathrm{~h}$. To find out the half maximal inhibitory concentration $\left(\mathrm{IC}_{50}\right)$ of $\mathrm{BV}$, cell viability was determined by MTT assay using various BV concentrations $(1,2.5,5,10$ and $15 \mu \mathrm{g} / \mathrm{ml})$. The results showed that cell viability was affected in a dose-dependent manner $(1-15 \mu \mathrm{g} / \mathrm{ml})$. The $\mathrm{IC}_{50}$ value of CaSki, HeLa and C33A was 9.8, 10.0 and $10.1 \mu \mathrm{g} / \mathrm{ml}$ after $12 \mathrm{~h}$ of BV treatment, respectively (Fig. 1A). After $24 \mathrm{~h}$ of BV treatment, the $\mathrm{IC}_{50}$ value was 5.4, 9.7 and $14.3 \mu \mathrm{g} / \mathrm{ml}$ in CaSki, HeLa and C33A, respectively (Fig. 1B). The represented data are means \pm SEM from three independent experiments and are expressed in terms of the control value. These data support the hypothesis that there is a significant difference in sensitivity to BV between HeLa and CaSki cells. In contrast, in the case of C33A, relatively less suppression of cell growth was observed, suggesting that inhibition of cell growth is mediated by antiviral effects of BV. 


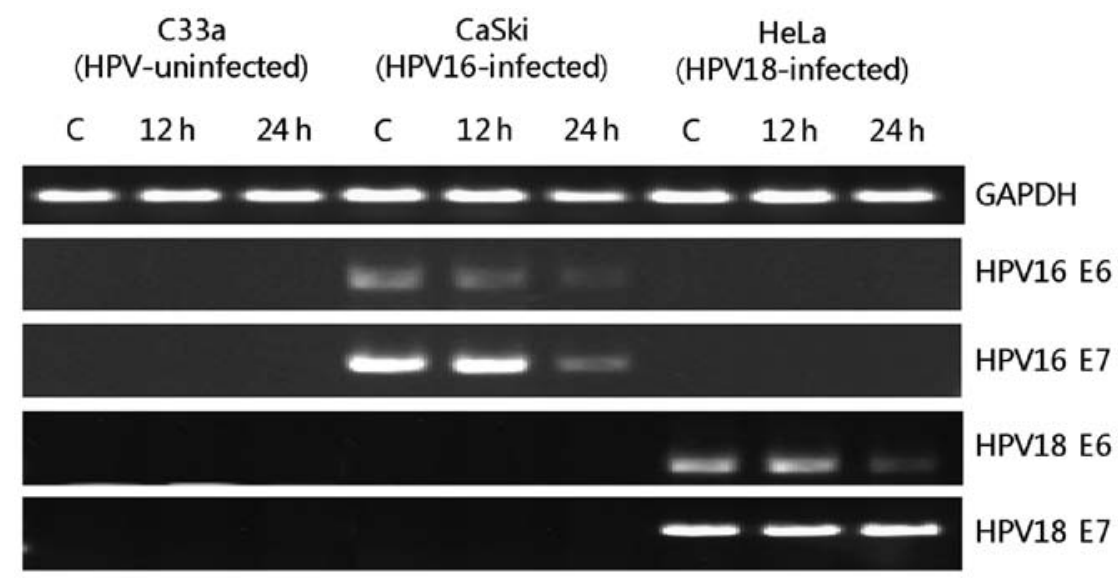

Figure 2. In vitro inhibition of HPV16/18 E6/E7 mRNA expression by BV using RT-PCR. Cells were treated with $10 \mu \mathrm{g} / \mathrm{ml}$ of BV. After 12 and $24 \mathrm{~h}$ of incubation, the cells were collected and total RNA was extracted from CaSki, HeLa and C33A cells. BV, bee venom.

A

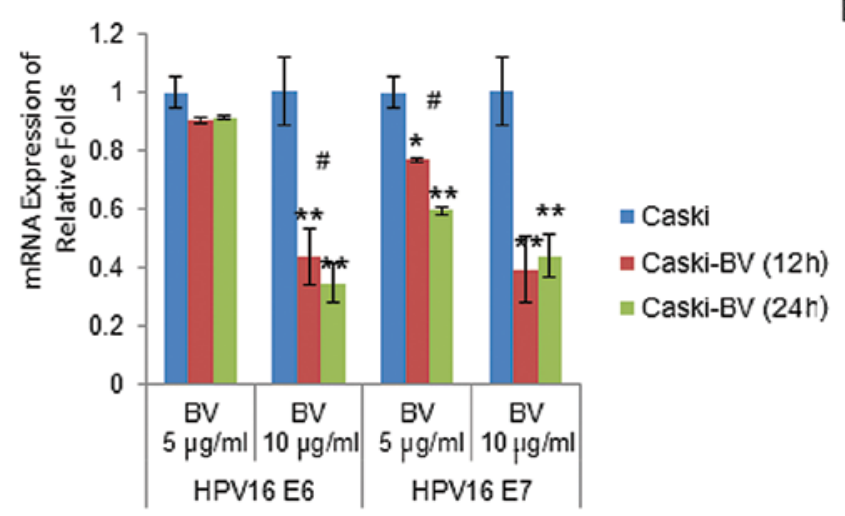

B

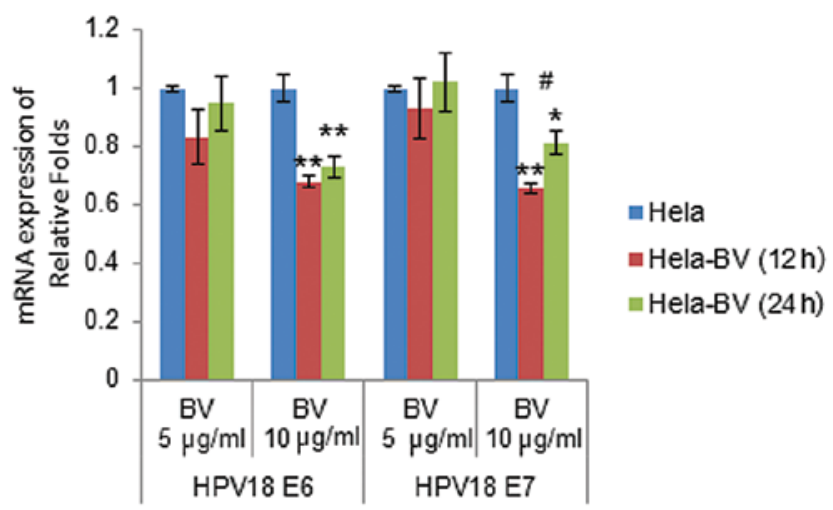

Figure 3. In vitro inhibition of HPV16/18 E6/E7 mRNA expression by BV using qRT-PCR. Cells were treated with $10 \mu \mathrm{g} / \mathrm{ml}$ of BV. After 12 and $24 \mathrm{~h}$ of incubation, the cells were collected and total RNA was extracted from (A) CaSki and (B) HeLa cells. Each bar represents a means \pm SD (vertical line) of three replicates. ${ }^{*} \mathrm{P}<0.05$ and ${ }^{* *} \mathrm{P}<0.01$ as compared with the control, respectively. ${ }^{\#} \mathrm{P}<0.05$ as compared between 12 and $24 \mathrm{~h}$ groups. $\mathrm{BV}$, bee venom.

Inhibition of HPV E6/E7 mRNA expression by $B V$. To examine whether BV treatment downregulates HPV E6/E7 mRNA expression in CaSki and HeLa cells, the levels of mRNA were analyzed by RT-PCR (Fig. 2). The mRNA expression of HPV16 E6 was gradually decreased until $24 \mathrm{~h}$ and that of HPV16 E7 was decreased at $24 \mathrm{~h}$ after $10 \mu \mathrm{g} / \mathrm{ml} \mathrm{BV}$ was treated to CaSki cells. In the case of HeLa, the mRNA expression of HPV18 E6 was decreased at $24 \mathrm{~h}$ after $10 \mu \mathrm{g} / \mathrm{ml}$ BV treatments but that of HPV18 E7 was not altered by BV. We also evaluated the mRNA expression by qRT-PCR that analyzed HPV16/18 E6/E7 mRNA expression levels as compared with GAPDH in BV-treated CaSki and HeLa cells. The mRNA expression levels were obtained for the threshold cycle $(\mathrm{Ct})$ for each gene and normalized using the average of the GAPDH gene and determined quantified relative folds. HPV16 E6 and E7 mRNA expressions were $0.90 \pm 0.01$ and $0.77 \pm 0.01$-fold after $12 \mathrm{~h}$, and $0.91 \pm 0.01$ and $0.59 \pm 0.01$-fold after $24 \mathrm{~h}$ in $5 \mu \mathrm{g} / \mathrm{ml} \mathrm{BV-treated}$ CaSki cells, respectively. In $10 \mu \mathrm{g} / \mathrm{ml} \mathrm{BV-treated} \mathrm{CaSki} \mathrm{cells,}$ the mRNA expression levels of HPV16 E6 and E7 were significantly decreased by BV: $0.44 \pm 0.10$ and $0.39 \pm 0.11$-fold (after $12 \mathrm{~h}$ ), and $0.35 \pm 0.06$ and $0.44 \pm 0.07$-fold (after $24 \mathrm{~h}$ ) in BV-treated CaSki cells (Fig. 3A). HPV18 E6 and E7 mRNA expression levels were not significantly altered by $5 \mu \mathrm{g} / \mathrm{ml}$
BV-treated HeLa cells. In $10 \mu \mathrm{g} / \mathrm{ml} \mathrm{BV-treated} \mathrm{HeLa} \mathrm{cells,}$ HPV18 E6 and E7 mRNA expressions were 0.68 \pm 0.02 and $0.66 \pm 0.02$-fold after $12 \mathrm{~h}$, and $0.73 \pm 0.03$ and $0.81 \pm 0.04$-fold after $24 \mathrm{~h}$, respectively (Fig. 3B). When the HPV16/18 E6/ E7 mRNA expression levels at $5 \mu \mathrm{g} / \mathrm{ml} \mathrm{BV-treatment} \mathrm{were}$ compared between CaSki and HeLa cells, more HPV16 E7 was observed in CaSki cells, as compared to HeLa cells. Moreover, when the cervical cancer cells were treated with $10 \mu \mathrm{g} / \mathrm{ml} \mathrm{BV}$, the inhibition of HPV16/18 E6/E7 mRNA expression levels was significantly observed. Collectively, these data further suggest that BV treatment can induce these different cell lines in a different manner.

Protein expression of HPV E6/E7 in CaSki and HeLa with BV treatments. To investigate whether HPV E6/E7 protein expression by BV treatment displayed a different level, we performed western blot analyses that estimated HPV16/18 E6/E7 protein expression as compared with $\beta$-actin. The protein expression levels were also quantified by densities of blotted bands and were measured by relative folds compared to those of HPV16/18 E6/E7 of BV-untreated CaSki and HeLa cells. In BV-treated CaSki and HeLa cells, the levels of these protein expressions were significantly lower than those of BV-untreated cells. 
A
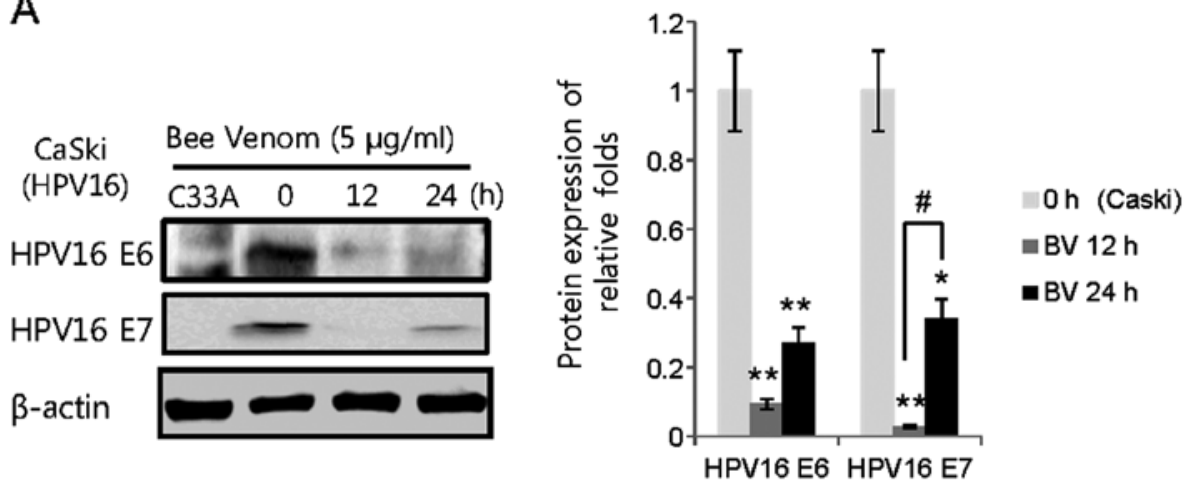

B

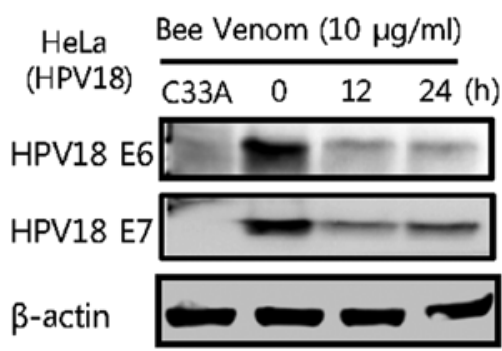

Figure 4. In vitro inhibition of HPV16/18 E6/E7 protein expression by BV using western blotting. After 12 and $24 \mathrm{~h}$ of incubation, the cells were collected and total RNA was extracted from (A) CaSki and (B) HeLa cells. ${ }^{*} \mathrm{P}<0.05$ and ${ }^{* *} \mathrm{P}<0.01$ as compared with the control, respectively. ${ }^{\#} \mathrm{P}<0.05$ as compared between 12 and $24 \mathrm{~h}$ groups. BV, bee venom.

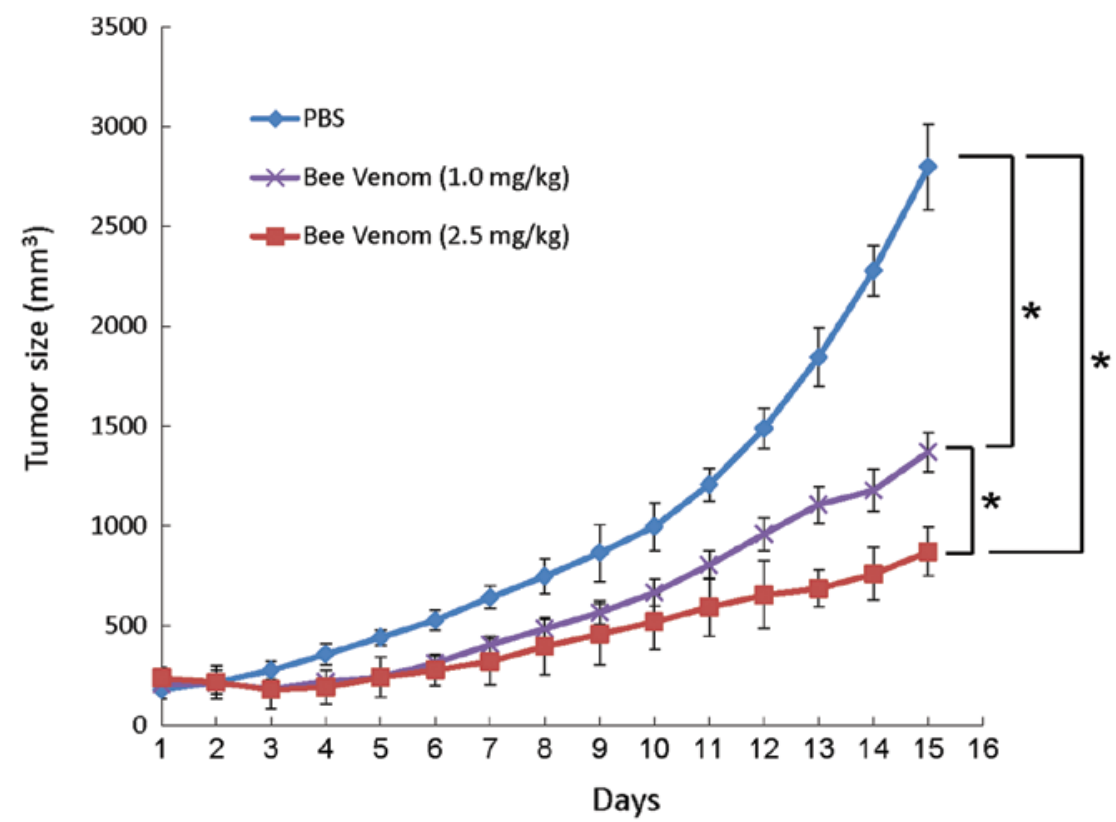

Figure 5. In vivo effect of $\mathrm{BV}$ on tumor growth inhibition in TC-1 cell-challenged C57BL/6 mice. Tumor growth curves for TC-1 of mice treated with BV. Tumor-bearing mice received intra-tumoral injection of BV or PBS. Each tumor size was monitored thereafter, as described in Materials and methods. ${ }^{*} \mathrm{P}<0.01$ as compared with the control group. BV, bee venom; PBS, phosphate-buffered saline.

Protein expressions of HPV16 E6 and E7 were significantly decreased at $5 \mu \mathrm{g} / \mathrm{ml} \mathrm{BV}$-treated CaSki cells for $24 \mathrm{~h}$, compared to the BV-treated CaSki cells for $12 \mathrm{~h}$ (Fig. 4A). In $10 \mu \mathrm{g} / \mathrm{ml}$
BV-treated HeLa cells, HPV18 E6 and E7 were less expressed at 12 and $24 \mathrm{~h}$ as compared to the expression of HPV16 E6 and E7 by BV-treated CaSki cells (Fig. 4B). These data support the 
A

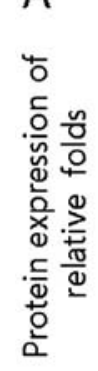

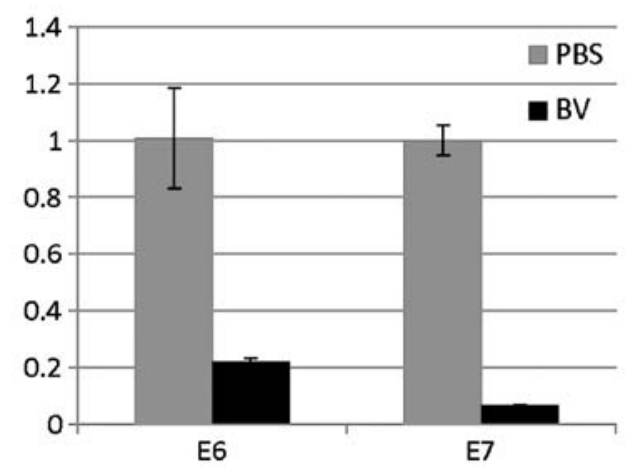

B

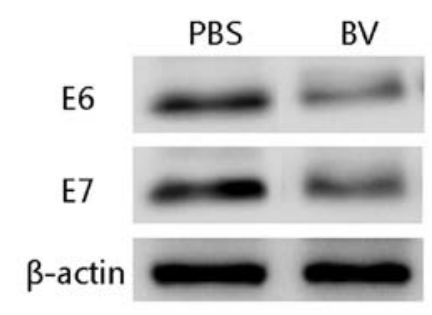

Figure 6. In vivo HPV E6/E7 expression levels in BV-treated TC-1 tumors. The HPV16 E6/E7 mRNA (A) and protein levels (B) were evaluated by qRT-PCR and western blotting, respectively. BV, bee venom.

theory that HPV16/18 E6 and E7 are downregulated by BV in the cervical cancer cells.

Antitumor effect of TC-1 tumor model by BV treatments. To determine the antitumor effects of $\mathrm{BV}$ in vivo, $\mathrm{C} 57 \mathrm{BL} / 6$ mice were challenged s.c. with TC-1 cells and then treated with BV. As shown in Fig. 5, BV treatment was initiated on day 1 when tumors were relatively small in size. The growth of TC-1 tumors was significantly decreased compared with that of tumors treated with PBS. Specifically, by day 15 after treatment, PBS-treated tumors reached an average tumor volume of $2,797 \pm 215 \mathrm{~mm}^{3}$, while those treated with $1 \mathrm{mg} / \mathrm{kg}$ of BV reached $1,369 \pm 98 \mathrm{~mm}^{3}$, and those treated with $2.5 \mathrm{mg} / \mathrm{kg}$ of $\mathrm{BV}$ reached $839 \pm 122 \mathrm{~mm}^{3}$. In addition, at day 15 after treatment, the $2.5 \mathrm{mg} / \mathrm{kg}$ BV-treated TC-1 tumor group showed that the tumor growth was significantly suppressed as compared with the $1.0 \mathrm{mg} / \mathrm{kg} \mathrm{BV}$-treated group $(\mathrm{P}<0.0001)$ and with the PBS group $(\mathrm{P}<0.0001)$. The antitumor effects of $\mathrm{BV}$ in vivo were consistent with the MTT assays and protein expression analyses in vitro.

HPV16 E6/E7 expression of TC-1 tumor model by BV treatments. To analyze HPV16 E6/E7 mRNA and protein levels in vivo by $\mathrm{BV}$ treatment in TC-1 tumors, we evaluated mRNA and protein expression by qRT-PCR and western blotting, respectively. The mRNA expression levels of HPV16 E6 and E7 were decreased by BV. HPV16 E6 gene in the TC-1 tumors was $0.22 \pm 0.02$-fold and E7 gene was $0.07 \pm 0.004$-fold compared with PBS-treated tumor (Fig. 6A). Protein expression levels of HPV16 E6 and E7 in the TC-1 tumors were significantly decreased by BV (Fig. 6B). Overall, these data suggest that BV treatments induce downregulation of HPV16 E6 and E7 depending on the cervical cancer cell lines.

\section{Discussion}

Cervical carcinoma is caused mostly by infection with a high-risk group of human papillomaviruses (HPVs). After high-risk HPV infection, E6 and E7 oncoproteins, which are essential for immortalization and transformation of human squamous epithelial cells, are consistently expressed. In HPV type 16, mutations on the open reading frame of E6 or E7, or on their upstream sequences, alter the oncogenicity of the virus, suggesting an important role of these viral proteins in oncogenesis. In most cervical cancers, the function of p53 is downregulated by the E6 protein of HPV16; E6 binds to p53 and leads to degradation of E6-p53 complexes due to E6-activated ubiquitin-dependent protease digestion. In the present study, we evaluated the effect of BV on cervical cancer cells to get an insight into the molecular basis of tumor-specific growth inhibition in vitro and in vivo. BV induced an increase in the levels of p53 and decreased the survival of cancer cells (16). BV downregulated the levels of anti-apoptotic genes such as Bcl-2 and Bcl-XS/L; however, the levels of Bax, a pro-apoptotic gene, were upregulated (23). Moreover, the efficacy of BV therapy has been confirmed clinically (14). We also observed a significant growth suppression of cervical cancer cells when BV was treated into the cells. In particular, HPV16-infected cell types were more susceptible to BV-mediated cell growth inhibition than HPV18-infected cell types. In one study, HPV16-infected cells ( $\mathrm{SiHa}, 1-2$ copies of HPV/cell) were more susceptible to growth inhibition exerted by adeno-associated virus, as compared to HPV18-infected cells (HeLa, 50 copies of HPV/cells) (24). In agreement with this, our study showed that CaSki cells (600 copies of HPV/ cell) resulted in more susceptibility to growth inhibition by BV treatments compared to HeLa cells. Furthermore, similar suppression of cancer cell growth was observed between C33A and HeLa cells after BV treatments, supporting the theory that the effects of $\mathrm{BV}$ were significantly mediated by the downregulation of E6/E7 protein of HPV 16. On the other hand, it was notable that there was local recurrence in mice from day 7. The loss of inhibitory properties of BV began with the increased expression of E6. A possible explanation for this may be that the continual release of E6 oncogene overcomes the inhibitory effects of $\mathrm{BV}$, suggesting BV treatments could be transient as the host immune system plays a major role in preventing sustained effects of BV. Thus, an advanced strategy in the development of long-term persistent effects of BV is required.

Although the mechanisms behind the antiviral activity of BV remain unclear, BV showed very similar inhibition of pro-inflammatory cytokines (25). It was reported that a BV-derived peptide could provide a scaffold for p53 inhibitors to treat cancer. Further studies are required to define a possible mechanism of the adenoviral p53-like anti-inflammatory activity of BV. Although BV treatment induced tumor suppressor p53 as well as cyclin-dependent kinase inhibitor 
p21WAF1/CIP1 expression in a dose-dependent manner, BV is not a well-defined inflammatory mediator. Melittin is known as one of the principal active components of $\mathrm{BV}$ and is a powerful stimulator of phospholipase A2 (26). Treatment of melittin also potently induced pro-apoptotic protein p53, Bax and caspase- 3 expression but decreased anti-apoptotic protein Bcl-2 expression (27). We also observed that p53 overexpression induced apoptosis in CaSki and HeLa cells, as determined by Annexin V staining (28). This is consistent with our observation that both CaSki and HeLa cells displayed cell death upon BV treatment with the downregulation of E6/E7 protein of HPV16/18, and BV treatment behaves differently in HeLa and CaSki cells. It could be suggested that, in these cells, endogenous p53 is not exhausted with the downregulation of viral E6 protein that binds to p53, resulting in degradation of p53-E6 complexes via the ubiquitin pathway. It was reported that treatment with adeno-associated virus induced different levels of cell growth inhibition among cervical cancer cell types (24), suggesting a different nature of each cervical cancer cell's HPV infection status.

$\mathrm{BV}$ plays an important role in maintaining regulation of pro-inflammatory cytokines and was suggested to be involved in distinct signaling pathways (29). For example, BV inhibited the expression of specific inflammatory genes that were upregulated by nuclear factor- $\kappa \mathrm{B}$ in the presence of LPS, including mitogen-activated protein kinase 8 (MAP3K8), TNF, TNF- $\alpha$-induced protein 3 (TNFAIP3), suppressor of cytokine signaling 3 (SOCS3), TNF receptor-associated factor 1 (TRAF1), JUN and CREB binding protein (CBP). However, it should be noted that BV could inhibit both proand anti-inflammatory cytokine expression $(4,30)$. It may be noteworthy to identify certain biological compounds in BV that are responsible for altering transcription expression of both inflammatory cytokines and the mechanism whereby BV induces growth arrest in different phases in cervical cells.

Taken together, we observed that BV treatments exert a differential effect in suppressing cervical cancer cell growth through the downregulation of E6/E7 protein of HPV16/18. In particular, HPV16-infected cells (CaSki cells) were more susceptible to growth inhibition exerted by BV, as compared to HPV18-infected cells (HeLa cells), suggesting that the growth inhibition phase is dependent on the cervical cancer cell line. Thus, these data support the hypothesis that BV plays an important role in suppressing cancer cell growth by the downregulation of E6/E7 protein of HPV16/18, depending on the cancer cell line.

\section{Acknowledgements}

We deeply thank PhD student Gantumur Battogtokh for his active advice and support. This study was supported by the National Research Foundation of Korea (NRF) grant funded by the Korean government (MEST) (NRF-2012R1A2A1A 03670430 and NRF-2013R1A1A2063115), the MSIP (Ministry of Science, ICT and Future Planning) under the 'IT Consilience Creative Program' (NIPA-2014-H0201-14-1002) supervised by the NIPA (National IT Industry Promotion Agency), and a grant (Industry-Academic Cooperation Foundation program) from Dong Sung Biopharm Co.

\section{References}

1. Billingham ME, Morley J, Hanson JM, Shipolini RA and Vernon CA: Letter: An anti-inflammatory peptide from bee venom. Nature 245: 163-164, 1973.

2. Orlov BN, Omarov ShM, Gelashvili DB, Korneva NV and Asafova NN: Chemistry and pharmacology of bee venom (a review of the literature). Farmakol Toksikol 41: 358-369, 1978 (In Russian).

3. Hockenhull J, Elremeli M, Cherry MG, et al: A systematic review of the clinical effectiveness and cost-effectiveness of Pharmalgen ${ }^{\circledR}$ for the treatment of bee and wasp venom allergy. Health Technol Assess 16: III-IV, 1-110, 2012.

4. Park HJ, Lee HJ, Choi MS, et al: JNK pathway is involved in the inhibition of inflammatory target gene expression and NF-kappaB activation by melittin. J Inflamm 5: 7, 2008.

5. Habermann E: Bee and wasp venoms. Science 177: 314-322, 1972.

6. Schmidt JO: Biochemistry of insect venoms. Annu Rev Entomol 27: 339-368, 1982.

7. Son DJ, Lee JW, Lee YH, Song HS, Lee CK and Hong JT: Therapeutic application of anti-arthritis, pain-releasing, and anti-cancer effects of bee venom and its constituent compounds. Pharmacol Ther 115: 246-270, 2007.

8. Texier C, Pouvelle S, Busson M, et al: HLA-DR restricted peptide candidates for bee venom immunotherapy. J Immunol 164: 3177-3184, 2000.

9. Kleinschmidt JH, Mahaney JE, Thomas DD and Marsh D: Interaction of bee venom melittin with zwitterionic and negatively charged phospholipid bilayers: a spin-label electron spin resonance study. Biophys J 72: 767-778, 1997.

10. Przybilla B: Insect venom allergy. Removing the sting of killer bees!. MMW Fortschr Med 143: 41-44, 2001 (In German).

11. Hong SJ, Rim GS, Yang HI, et al: Bee venom induces apoptosis through caspase- 3 activation in synovial fibroblasts of patients with rheumatoid arthritis. Toxicon 46: 39-45, 2005.

12. Park MH, Choi MS, Kwak DH, et al: Anti-cancer effect of bee venom in prostate cancer cells through activation of caspase pathway via inactivation of NF-KB. Prostate 71: 801-812, 2011.

13. Park JH, Kim KH, Kim SJ, Lee WR, Lee KG and Park KK: Bee venom protects hepatocytes from tumor necrosis factor- $\alpha$ and actinomycin D. Arch Pharm Res 33: 215-223, 2010.

14. Liu XD, Zhang JL, Zheng HG, Liu FY and Chen Y: Clinical randomized study of bee-sting therapy for rheumatoid arthritis. Zhen Ci Yan Jiu 33: 197-200, 2008 (In Chinese).

15. Ip SW, Liao SS, Lin SY, et al: The role of mitochondria in bee venom-induced apoptosis in human breast cancer MCF7 cells. In Vivo 22: 237-245, 2008.

16. Ip SW, Wei HC, Lin JP, et al: Bee venom induced cell cycle arrest and apoptosis in human cervical epidermoid carcinoma Ca Ski cells. Anticancer Res 28: 833-842, 2008.

17. Han HJ, Lee JH, Park SH, et al: Effect of bee venom and its melittin on apical transporters of renal proximal tubule cells. Kidney Blood Press Res 23: 393-399, 2000.

18. Hood JL, Jallouk AP, Campbell N, Ratner L and Wickline SA: Cytolytic nanoparticles attenuate HIV-1 infectivity. Antivir Ther 18: 95-103, 2013.

19. Fenard D, Lambeau G, Maurin T, Lefebvre JC and Doglio A: A peptide derived from bee venom-secreted phospholipase $A_{2}$ inhibits replication of T-cell tropic HIV-1 strains via interaction with the CXCR4 chemokine receptor. Mol Pharmacol 60: 341-347, 2001.

20. Soman NR, Baldwin SL, Hu G, et al: Molecularly targeted nanocarriers deliver the cytolytic peptide melittin specifically to tumor cells in mice, reducing tumor growth. J Clin Invest 119: 2830-2842, 2009.

21. Jemon K, Young V, Wilson M, et al: An enhanced heterologous virus-like particle for human papillomavirus type 16 tumour immunotherapy. PLoS One 8: e66866, 2013.

22. Kim YW, Bae SM, Battogtokh G, Bang HJ and Ahn WS: Synergistic anti-tumor effects of combination of photodynamic therapy and arsenic compound in cervical cancer cells: in vivo and in vitro studies. PLoS One 7: e38583, 2012.

23. Kim SK, Park KY, Yoon WC, et al: Melittin enhances apoptosis through suppression of IL-6/sIL-6R complex-induced NF- $\kappa B$ and STAT3 activation and Bcl-2 expression for human fibroblastlike synoviocytes in rheumatoid arthritis. Joint Bone Spine 78: 471-477, 2011. 
24. Su PF and Wu FY: Differential suppression of the tumorigenicity of HeLa and SiHa cells by adeno-associated virus. Br J Cancer 73: 1533-1537, 1996.

25. Kwon YB, Kim HW, Ham TW, et al: The anti-inflammatory effect of bee venom stimulation in a mouse air pouch model is mediated by adrenal medullary activity. J Neuroendocrinol 15: 93-96, 2003.

26. Ownby CL, Powell JR, Jiang MS and Fletcher JE: Melittin and phospholipase $\mathrm{A}_{2}$ from bee (Apis mellifera) venom cause necrosis of murine skeletal muscle in vivo. Toxicon 35: 67-80, 1997.

27. Son DJ, Ha SJ, Song HS, et al: Melittin inhibits vascular smooth muscle cell proliferation through induction of apoptosis via suppression of nuclear factor- $\kappa \mathrm{B}$ and Akt activation and enhancement of apoptotic protein expression. J Pharmacol Exp Ther 317: 627-634, 2006
28. Ahn WS, Han YJ, Bae SM, et al: Differential suppression of human cervical cancer cell growth by adenovirus delivery of p53 in vitro: arrest phase of cell cycle is dependent on cell line. Jpn J Cancer Res 93: 1012-1019, 2002.

29. Jang HS, Chung HS, Ko E, et al: Microarray analysis of gene expression profiles in response to treatment with bee venom in lipopolysaccharide activated RAW 264.7 cells. J Ethnopharmacol 121: 213-220, 2009.

30. Han S, Lee K, Yeo J, et al: Effect of honey bee venom on microglial cells nitric oxide and tumor necrosis factor- $\alpha$ production stimulated by LPS. J Ethnopharmacol 111: 176-181, 2007. 